\title{
Christian Quintes, Traumtheorien und Traumpoetiken der deutschen Romantik
}

\section{Claire Gantet}

\section{OpenEdition}

Journals

Édition électronique

URL : http://journals.openedition.org/ifha/10828

DOI : $10.4000 /$ ifha. 10828

ISSN : 2198-8943

\section{Éditeur}

IFRA - Institut franco-allemand (sciences historiques et sociales)

\section{Référence électronique}

Claire Gantet, "Christian Quintes, Traumtheorien und Traumpoetiken der deutschen Romantik », Revue de I'IFHA [En ligne], Date de recension, mis en ligne le 26 juin 2020, consulté le 24 septembre 2020. URL : http://journals.openedition.org/ifha/10828; DOI : https://doi.org/10.4000/ifha.10828

Ce document a été généré automatiquement le 24 septembre 2020

(CIFHA 


\title{
Christian Quintes, Traumtheorien und Traumpoetiken der deutschen Romantik
}

\author{
Claire Gantet
}

\section{RÉFÉRENCE}

Christian Quintes, Traumtheorien und Traumpoetiken der deutschen Romantik, Würzburg : Königshausen \& Neumann, 2019, 348 p., $48 €$

Il faut une certaine audace pour s'attaquer au rêve dans le romantisme allemand, tant il a été l'objet d'études. C'est ce défi que relève Christian Quintes qui y consacre sa thèse en études allemandes réalisée à l'Université de la Sarre, dans le cadre de l'école doctorale sur les Cultures européennes du rêve dirigée par Manfred Engel. Les études sur le sujet n'auraient donné lieu qu'à des articles ou à contributions isolés et il n'existerait aucune monographie sur le sujet, argumente $C$. Quintes qui ignore notamment L'Âme romantique et le rêve d'Albert Béguin (1967, $1^{\mathrm{e}}$ éd. 1937), pourtant traduit en allemand. On le sait, les romantiques eurent une attitude bifrons envers cet objet : ils ont nourri une fascination pour le rêve comme ressource poétique et expression d'une régression vers un élément de la nature antérieur à l'individualité, mais aussi un désintérêt relatif pour la psyché individuelle et les rêves personnels. C. Quintes entend aller plus loin que ce constat déjà bien connu en resituant les auteurs qu'il étudie (il centre son propos sur E.T.A. Hoffmann, Clemens Brentano et Joseph von Eichendorff) et en les mettant en perspective par rapport aux enquêtes majeures sur le rêve menées par des médecins philosophes comme Gotthilf Heinrich Schubert, Ignaz Paul Vitalis Troxler et Carl Gustav Carus.Les principaux résultats de l'analyse consistent à évoquer certaines continuités entre l'Aufklärung et le romantisme : l'idée selon laquelle la vie endormie est déficitaire par rapport à la vie éveillée (C. Quintes reprend là une formulation avec laquelle Manfred Engel qualifiait la définition négative du rêve par l'absence de cohérence) mais aussi l'intuition que le rêve dit quelque chose de la psyché, et enfin la conception d'une symbolique du rêve, que $C$. Quintes fait remonter à la Mésopotamie antique. L'auteur souligne ensuite les «théories » proprement romantiques du rêve. 
Novalis a lancé un débat sur la valeur du rêve avec son roman fragmentaire Heinrich von ofterdingen (1800), dans lequel Heinrich, un troubadour du XIII ${ }^{e}$ siècle, rêve de la fleur bleue (ou bleuet), une fleur merveilleuse promettant l'accès à des trésors. Comme on pouvait s'y attendre, Novalis ne développe pas une théorie du rêve, mais rapproche le songe du domaine des légendes, des contes, de la mythologie. Les " théoriciens " Schubert, Troxler et Carus n'envisagent, eux, le rêve que dans le cadre d'une cosmologie englobante. Schubert rapporte la similitude des symboles oniriques, des images poétiques et du langage imagé de la Bible à une symbolique originelle hiéroglyphique de la nature qu'il interprète en termes chrétiens, sans chercher plus avant la signification de ces symboles. Il est largement reçu chez Eichendorff et Hoffmann : la littérature et la science puisent aux mêmes sources. Les poétiques suivent aussi des schémas récurrents, en particulier un modèle historique triadique progressif (âge d'or passé, présent déficient, futur plus élevé), et la mise en abyme. C. Quintes consacre une analyse aux figures du rêveur et aux instances narratives. Il souligne que chez les romantiques, le rêve a souvent une fonction satirique qui prend des aspects très divers, souvent actuels. Il souligne enfin l'intrusion progressive d'éléments fantastiques dans le rêve.C. Quintes a rassemblé dans sa thèse des éléments présents de façon éparse dans la recherche. En dépit de l'intérêt évident du sujet, on ne peut malheureusement cacher sa déception à la lecture de son livre. La démarche consistant à étudier de pair la littérature et des textes scientifiques, d'anthropologie ou de psychologie comme on le dit alors, n'est en rien nouvelle. On pense par exemple à l'excellente étude de Walter Hinderer, «Traumdiskurse und Traumtexte im Umfeld der Romantik » (in Gabriele Brandstetter et Gerhard Neumann [dir.], Romantische Wissenspoetik, 2004, p. 213-241). Le postulat de départ qu'hormis chez Calderón (La vida es sueño, 1636), la veille et le rêve sont clairement distingués avant le romantisme aurait mérité développement et justification. Il semble bien au contraire que la littérature ait fréquemment joué sur les frontières incertaines du rêve. De même, on regrette l'absence de toute définition contextuelle du terme de «symbolique » ou Symbolik (ainsi dans le Dictionnaire allemand des frères Grimm) qui aurait jeté une tout autre lumière sur l'ouvrage de Schubert et sur l'herméneutique du songe. L'origine des spéculations sur les hiéroglyphes n'est pas plus approfondie. Le somnambulisme joue bien sûr un rôle important, mais là non plus, l'auteur n'est pas au fait de la recherche récente. Enfin, il aurait pu préciser ce qu'il entend par le terme de « théorie » et comment il le distingue des « représentations ». C. Quintes a effectué sa thèse en trois ans. Un laps de temps plus long lui aurait certainement permis d'approfondir son étude.

\section{INDEX}

Thèmes : Histoire de la culture

Index chronologique : Période moderne 


\section{AUTEURS}

\section{CLAIRE GANTET}

Université de Fribourg (Suisse)/Universität Freiburg (Schweiz) 